\title{
Effects of Greenshipping to the Maritime Industry
}

\author{
Ezenwa A. Ogbonnaya \\ Department of Mech/Marine \\ Engineering, Niger Delta University, \\ Wilberforce Island, \\ Bayelsa State.Nigeria. \\ Ezenwaogbonnaya@yahoo.com
}

\author{
Robert Poku \\ Department of Mech/Marine \\ Engineering, Niger Delta University, \\ Wilberforce Island, \\ Bayelsa State.Nigeria. \\ Robertpoku@yahoo.com
}

\author{
Emmanuel M. Adigio \\ Department of Mech/Marine \\ Engineering, Niger Delta University, \\ Wilberforce Island, \\ Bayelsa State.Nigeria. \\ Emadigio@yahoo.com
}

\begin{abstract}
In order to keep focus on the important agenda of sustainability which has lately become an issue of priority, the maritime industry must implement technologies on existing vessels and on those under construction so as to reduce their emissions into the environment. This study examines three potential sources of emission and also identifies a set of emission control measures that are available and could, if fully applied, reduce emission by $19.058 \%$. With the waste heat recovery system, about $2500 \mathrm{~kW}$ of energy are saved, thereby increasing the efficiency to $59.11 \%$ having about $10.13 \%$ gain compared to engines without a waste heat recovery system. It is therefore recommended that the use of waste heat recovery systems should be encouraged on marine vessels to reduce the impact of noxious gasses into the atmosphere.
\end{abstract}

Keywords- greenshipping; maritime industry; exhaust emission control; single pressure waste heat recovery system; exhaust gas waste heat recovery

\section{NOMENCLATURE}

$\begin{array}{ll}\mathrm{BC} & \text { Black Carbon } \\ \mathrm{CO} \mathrm{O}_{x} & \text { Carbon oxides } \\ \mathrm{HC} & \text { Hydrocarbon } \\ \mathrm{LCV} & \text { Lower Calorific Value } \\ m_{f} & \text { Mass flow rate of fuel } \\ N O_{x} & \text { Nitrogen oxides } \\ \text { s.f.c } & \text { specific fuel consumption } \\ S O_{x} & \text { Sulphur oxides } \\ W_{b} & \text { Brake power } \\ \text { EGWHR } & \text { Exhaust Gas Waste Heat Recovery } \\ \text { SECA } & \text { Sulphur Emission Control Area } \\ \text { N } & \text { Nigerian Naira }\end{array}$

\section{INTRODUCTION}

Today, ninety percent of the world trade is carried by ship and for the vast majority of this trade, there is little or no transport alternative [1]. Ships can carry large quantities of cargo with high efficiency. With the rapid growth of economies of developing nations, e.g. in Asia, trading activity is increasing and along with it comes an increase in ship traffic and the need for large ships that are able to carry more cargo.
This creates a need for balanced economic growth and also for improving and maintaining the air quality. It is estimated that $2.7 \%$ of the global carbon dioxide emission comes from international shipping. It is inevitable that ships contribute to unwanted emissions as they use bunker fuel which contains high level sulphur, ash and nitrogen compound and generate higher emissions than distillate fuel. To make matters worse, they use unrefined fuel, the dirtiest in the market, thus emitting various global warming pollutans which include $\mathrm{CO}_{\mathrm{x}}, \mathrm{SO}_{\mathrm{x}}$, $\mathrm{HC}_{\mathrm{x}}$ and $\mathrm{NO}_{\mathrm{x}}$. These pollutants all contribute to global climate change either directly by acting as agents that trap heat in the atmosphere or indirectly by aiding the creation of additional Green House Gases (GHG) [2, 3].

Exhaust emissions sends out tiny particles which are too small for the human upper respiratory system to filter from the air when we breathe [1]. They go deep into the lungs, where they may cause damage and chemical changes. Similarly, the Volatile Organic Compounds (VOCs) are not left out. VOCs are chemicals that contain organic carbon and they readily evaporate, changing from liquids to gas when exposed to air. VOCs may produce health effects if humans are exposed to high enough concentrations of them [4]. Lastly equipment such as refrigerators, air conditioners, fire extinguishers etc are also sources of emission. These equipment use fluids in their operations which are toxic and could deplete stratospheric ozone. Hence, they also produce GHG which deplete the ozone layer [5]. Some existing measures for the reduction of emission from ships are:

\section{A. Water Base Control}

Water base control is a measure through which the emission from the diesel engine is reduced by introducing water into the combustion chamber at different stages of the combustion process. This is to reduce the maximum peak combustion temperature and the formation of $\mathrm{NO}_{\mathrm{x}}, \mathrm{SO}_{\mathrm{x}}$ and $\mathrm{CO}_{\mathrm{x}}$.

\section{B. Seawater Scrubbing Technology}

Seawater scrubbing technology utilizes the natural alkalinity of seawater to reduce the $\mathrm{SO}_{\mathrm{x}}$ emission from the exhaust stream [6]. The solid particles are removed from the mixture and the seawater is then returned to the ocean, which is 
a natural reservoir as it contains high qualities of sulphur. The scrubbing provides an alternative to fuel switching for vessel operators traveling in SECA. Fuel switching is a simple approach to reduce energy consumption and costs for endusers, as well as curbing carbon emissions [6]. The seawater scrubbing technology has been found to reduce exhaust gas $\mathrm{SO}_{2}$ levels by $69-94 \%$ from vessels operating on fuel with a sulphur content of $2.5 \%$.

\section{Selective catalytic reduction:}

The selective catalytic reduction (SCR) process is another procedure to reduce the emission of toxic waste gases into the atmosphere. The configuration involves injecting a reagent such as ammonia or urea into the exhaust stream which then passes through a catalyst to achieve about $90 \%$ upward reduction of $\mathrm{NO}_{\mathrm{x}}$ [6].

\section{Exhaust Gas Scrubber}

Exhaust Gas Scrubber is used for washing exhaust gas from the engine. With the exhaust scrubbing system, it is possible to reduce the sulphur emissions to a level as low as if low sulphur fuel oil was used [1]. But because low sulphur fuel oil has a significantly higher cost price, it makes good financial sense to use scrubbers to clean off the exhaust gas and thereby continue using heavy fuel oil. Dry scrubber uses a catalyst to remove toxic components by chemisorptions or adsorption to their surface. The required contact time is very short and does not depend on the inlet concentration [7].

\section{MATERIALS AND METHODS}

The EGWHR system has been found to be a beneficial contributor to the reduction of $\mathrm{CO}_{2}$ emissions from ships as well as lowering the fuel cost. One of the ways this can be done is by utilizing the waste heat into electric power [8]. The Waste Heat Recovery System (WHRS) consists of an exhaust gas boiler and a supplying steam to a steam turbine. The steam turbine is connected to a generator, and thereby the waste heat is recovered as electrical energy. To obtain the highest electrical production, the optimal solution is to use a dual steam pressure system for exhaust gas recirculation [9].

Data were obtained from Sulzer engine RLB-66 specification Single Pressure Waste Heat Recovery System (SPWHRS) logbook [10], containing inventory records of monthly energy generation and operational statistics.

\section{A. Calculations of the mass flow rate of fuel}

To measure the amount of energy input, the value of mass flow rate of fuel was derived and is used to multiply the calorific value of fuel to get the amount of energy input.

$$
\begin{aligned}
& m_{f}=\frac{s . f . c \times W_{b}}{3600} \\
& m_{f}=\frac{0.175 \times 12080}{3600}=0.5872 \mathrm{~kg} / \mathrm{s}
\end{aligned}
$$

\section{B. Amount of energy input to system}

The amount of energy input to the system due to fuel combustion is given as:

$$
Q_{\text {input }}=m_{f} L C V
$$

where

$$
Q_{\text {input }}=\text { Energy supplied due to combustion of fuel }
$$

$$
L C V=\text { Lower calorific value of fuel }=4200 \mathrm{~kJ} / \mathrm{kg}
$$

$$
m_{f}=\text { Mass flow rate of fuel }=0.5872 \mathrm{~kg} / \mathrm{s}
$$

Therefore

$$
Q_{\text {input }}=0.5872 \times 4200=24663.33 \mathrm{~kW} .
$$

\section{Efficiency and Cost Analysis}

The efficiency of the main engine is given as

$$
\begin{aligned}
\eta_{M E} & =\frac{E_{\text {output }}}{E_{\text {input }}} \\
& =\frac{12080}{0.4898}=24663.33 \mathrm{~kW}
\end{aligned}
$$

Efficiency of SPWHRS is given as:

$$
\begin{aligned}
\eta_{S P} & =\eta_{M E}+\eta_{l p}\left(1-\eta_{M E}\right) 0.2337 \\
& =0.4898+0.85(1-0.4898) 0.2337 \\
& =59.11 \%
\end{aligned}
$$

where $\eta_{l p}$ is the efficiency of the low pressure steam drum. Also, the efficiency gained as a result of SPWHRS is given as:

$$
\begin{gathered}
\eta_{\text {gain }}=\eta_{S P}-\eta_{M E} \\
\eta_{\text {gain }}=59.11-48.98=10.13 \%
\end{gathered}
$$

The energy saved by using SPWHRS is given by:

$$
\begin{gathered}
\text { Energy saved }=\eta_{\text {gain }} \times E_{\text {input }} \\
=0.1013 \times 24663.33 \mathrm{~kW} \\
=2500 \mathrm{~kW}
\end{gathered}
$$

Amount of fuel saved per day for SPWHRS is given as:

$$
\begin{aligned}
m_{f} & =\frac{\text { s.f.c } \times E_{\text {save }} \times \text { time }}{\text { fuel density }} \\
& (7) \\
m_{f} & =\frac{0.175 \times 2500 \times 24}{0.86} \\
& =12209.302 \text { litres per day }
\end{aligned}
$$

Therefore, the amount of fuel saved per year for SPWHRS is: Liters saved per year $=m_{f}$ per day $x 365=4,456,395.35 \mathrm{lt}$ 
But if a liter costs 97.00, then the cost saved is:

$$
\begin{aligned}
& \text { Cost saved per day }=\begin{array}{lllll} 
& \text { x } & 12209.30
\end{array} \\
& =\# 1,184,302.1 \text {. }
\end{aligned}
$$

Cost saved per year $=\# 432,270,266.5$

However, at normal operating condition without WHRS, the amount of fuel used per day will be

$$
m_{f}=\frac{\text { s.f.c } \times E_{\text {normal }} \times \text { time }}{\text { density of the fuel }}=120448.821 \text { litres per day }
$$

The cost of 120448.821 litres per day will be:

$$
\begin{aligned}
& =\$ 97 \times 120448.821 \\
& =\$ 11,683,535.64 \text { per day. }
\end{aligned}
$$

Cost of running per year $=\# 4,264,490,508$ per year

The cost used to run the SPWHRS is:

$$
\begin{aligned}
C_{\text {single }} & =C_{\text {normal }}-C_{\text {saved }} \\
& =111,683,535.63-11,184,302.1 \\
& =£ 10,499,233.54 \text { per day }
\end{aligned}
$$

The cost used to run the SPWHRS per year is

$$
\begin{aligned}
C_{\text {single }} & =10,499,233, .54 \times 365 \\
& =\circledast 3,832,220,240.0 \text { per year } .
\end{aligned}
$$

D. Percentage decrease of heat transfer to exhaust gas Heat transfer to exhaust due to single pressure WHRS

$$
\begin{aligned}
Q_{\text {single pressure }} & =E_{\text {normal }}-E_{(\text {saved) single pressure }} \\
& =4700.4 \mathrm{~kW}
\end{aligned}
$$

Percentage heat transfer to exhaust gas ( $\left.\% Q_{g}\right)$ due to SPWHRS:

$$
\begin{gathered}
\% Q_{g(s p)}=\frac{Q_{g(s p)}}{E_{\text {input }}} \times 100 \\
\% Q_{g(s p)}=19.058 \%
\end{gathered}
$$

The $\%$ decrease of heat transfer to exhaust gas $\left(\% Q_{g}\right)$ due to SPWHRS:

$$
\text { \%decrease }\left(Q_{g}\right)=(29.19-19.058) \%=10.132 \%
$$

\section{RESULTS AND DISCUSSION}

A summary of the calculations obtained between equations 1 to 7 is shown in Table I. The analysis covered the areas of efficiency, energy and fuel saving cost, heat transfer and exhaust emission. The calculated savings are based on the SPWHRS. The WHRS helps in the reduction of the operating cost and the emission rate. The graphs shown in Figures 1 to 4 depict how the reductions in emission rates are achieved.

Comparing the maximum brake power output of $12080 \mathrm{~kW}$ and efficiency of $48.98 \%$ of the total energy supplied to the combined heat dissipated by charge air cooler, jacket water cooler and exhaust shows that about $51.02 \%$ of the total heat supplied was wasted. However, with the installation of the WHRS, part of this wasted heat was recovered.

TABLE I. SUMMARY OF THE SPWHRS

\begin{tabular}{|c|c|c|}
\hline $\mathbf{s} / \mathbf{n}$ & Items & Single (WHRS) \\
\hline $\mathbf{1}$ & Efficiency & $59.11 \%$ \\
\hline $\mathbf{2}$ & Efficiency gain & $10.13 \%$ \\
\hline $\mathbf{3}$ & Energy saved & $2,500 \mathrm{~kW}$ \\
\hline $\mathbf{4}$ & Amount of fuel saved per day & 12209.302 litres \\
\hline $\mathbf{5}$ & Cost saved per day & $1,184,302.10$ \\
\hline $\mathbf{6}$ & Amount of fuel saved per year for SPWHRS & $4,456,395.35$ litres \\
\hline $\mathbf{7}$ & Cost saved per year & $432,270,266.50$ \\
\hline $\mathbf{8}$ & Cost used to run SPWHRS per day & $470,499,233.30$ \\
\hline $\mathbf{9}$ & Heat transfer to exhaust & $19.058 \%$ \\
\hline $\mathbf{1 0}$ & \%Heat transfer to exhaust & $10.132 \%$ \\
\hline $\mathbf{1 1}$ & \%Decrease of heat transfer to exhaust & 12209.320 litres/day \\
\hline $\mathbf{1 2}$ & Amount of fuel required to run &
\end{tabular}

\section{A. Effiiciency Increase with SPWHRS}

The efficiency of the main engine without the WHRS is about $48.98 \%$ but with the installation of a SPWHRS, the efficiency became $59.11 \%$ having about $10.13 \%$ as compared to engine without waste heat.

\section{B. Impact of SPWHRS on Cost}

In the cost analysis, the input at normal operation is $24663.33 \mathrm{~kW}$ with about 120,449 litres of fuel per day is required to run at normal operating condition amounting to 11,683,535.64 per day. With the installation of SPWHRS about $2500 \mathrm{~kW}$ of saved energy is observed.

\section{C. Exhaust Gas Analysis}

More so, in the exhaust gas analysis, with the energy input at normal operation of $24663.33 \mathrm{~kW}$, about $29.19 \%$ of the total heat input is lost to the atmosphere as exhaust gas. With the installation of the single pressure WHRS the exhaust gas to the atmosphere is reduced to $19.058 \%$ of the total input energy

1) Analysis of $\mathrm{NO}_{x}$ emission

Table II is a summary of $\mathrm{NO}_{\mathrm{x}}$ emission in terms of water per ship speed and reagent per ship speed. Figures 1 and 2 emanated from table 2. The graphs also show that there is an inverse relationship between $\mathrm{NO}_{\mathrm{x}}$ emission versus water per ship speed and $\mathrm{NO}_{\mathrm{x}}$ emission versus reagent per ship speed. This implies that, to reduce $\mathrm{NO}_{\mathrm{x}}$ emission, water per ship speed and reagents per ship speed have to be high.

Figure 1 shows how injection process is used to reduce the emission of $\mathrm{NO}_{\mathrm{x}}$ as the speed increases. This system reduces the $\mathrm{NO}_{\mathrm{x}}$ formation by $50-60 \%$. Figure 2 is the SCR process where reagents such as ammonia or urea are injected into the exhaust stream, which then passes through a catalyst to achieve upwards of $90 \% \mathrm{NO}_{\mathrm{x}}$ reduction. 
TABLE II. SUMMARY OF $N O_{x}$ EMISSION

\begin{tabular}{|c|c|c|}
\hline $\begin{array}{c}N O_{x} \\
\text { emission }\end{array}$ & $\begin{array}{c}\text { Water per ship } \\
\text { speed }\end{array}$ & $\begin{array}{c}\text { Reagent per ship's } \\
\text { speed }\end{array}$ \\
\hline 8 & 2000 & 2000 \\
\hline 10 & 1500 & 1500 \\
\hline 12 & 1000 & 1000 \\
\hline 14 & 500 & 500 \\
\hline 16 & 100 & 100 \\
\hline
\end{tabular}

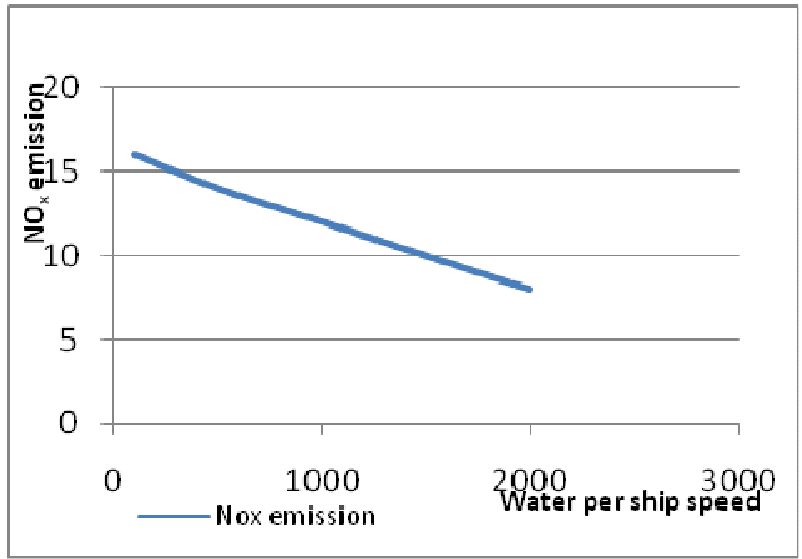

Fig. 1. Rate of $N O_{x}$ emission

Figure 3 illustrates the impact of seawater scrubbing technology. This technology utilizes the natural alkalinity of seawater to reduce the $\mathrm{SO}_{\mathrm{x}}$ emission from the exhaust stream. This technology has been found to reduce exhaust gas $\mathrm{SO}_{2}$ level by $69-94 \%$ from vessels operating on fuel with a sulphur content of $2.5 \%$.

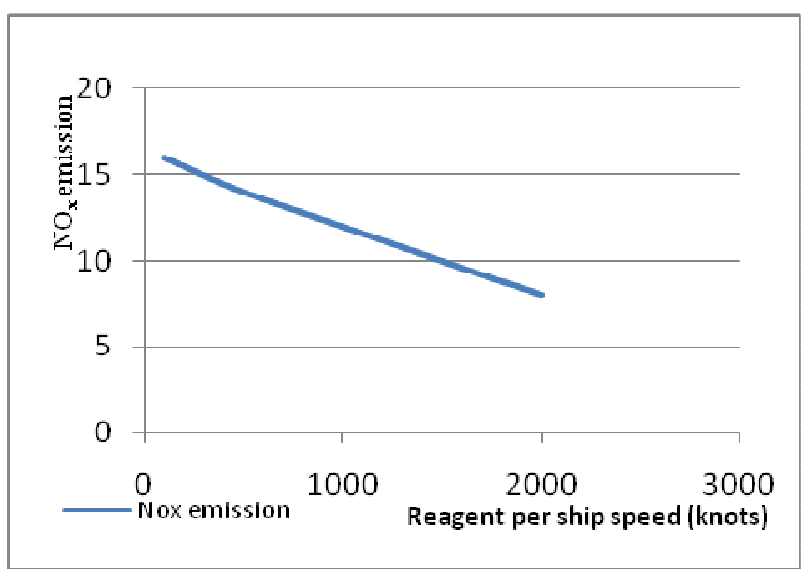

Fig. 2. $N O_{x}$ emission to reagent per ship speed

Figure 4 shows fuel switching process. This is suitable for vessels operating in regions that are defined as sulphur emission control area under the IMO Annex VI and have options for complying with the requirement of the regulation.

2) Analysis of $\mathrm{SO}_{x}$ emission

Table III is a summary of $\mathrm{SO}_{\mathrm{x}}$ emission in terms of exhaust emission per speed and fuel switching emission per speed.
Figures 3 and 4 were obtained from table 3 which show the inverse relationship between $\mathrm{SO}_{\mathrm{x}}$ emission and exhaust emission per ship speed and emission per ship speed respectively. This again implies that, to reduce $\mathrm{SO}_{\mathrm{x}}$ emission, ship speed must be increased.

TABLE III. SUMMARY OF $S O_{x}$ EMISSION

\begin{tabular}{|c|c|c|}
\hline$S O_{x}$ emission & $\begin{array}{c}\text { Exhaust } \\
\text { emission per } \\
\text { speed }\end{array}$ & $\begin{array}{c}\text { Fuel switching emission per } \\
\text { speed }\end{array}$ \\
\hline 8 & 2000 & 2000 \\
\hline 10 & 1500 & 1500 \\
\hline 12 & 1000 & 1000 \\
\hline 14 & 500 & 500 \\
\hline 16 & 100 & 100 \\
\hline
\end{tabular}



Fig. 3. Exhaust emission per speed

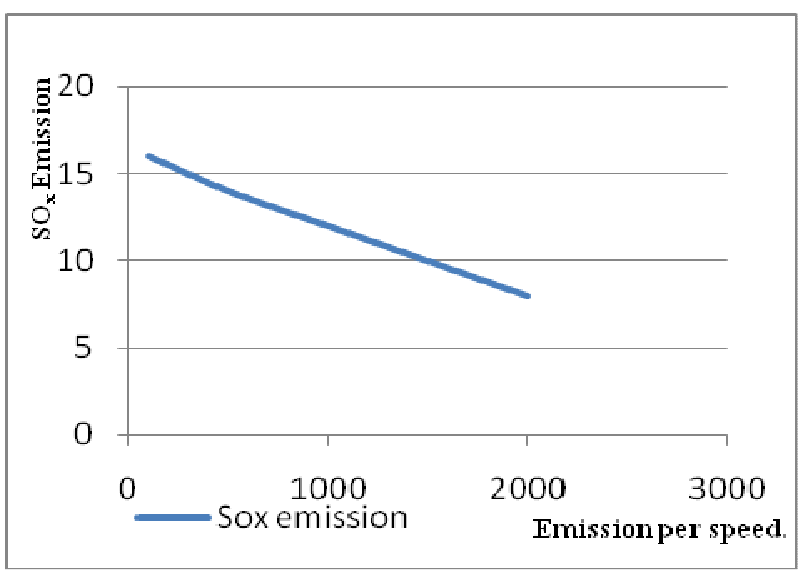

Fig. 4. Fuel switching emission per speed

3) $C O_{x}$ analysis

Table IV shows the relationship between the $\mathrm{CO}_{\mathrm{x}}$ emission and the density of air per speed. It is seen that an increase in the density of air per speed will cause a reduction in $\mathrm{CO}_{\mathrm{x}}$ emissions. Figure 5 shows the inverse relationship between the $\mathrm{CO}_{\mathrm{x}}$ emission and the density of air per speed. Hence, passing the charge air through an air cooler yield great advantage regarding $\mathrm{CO}_{\mathrm{x}}$ emission. 
TABLE IV. EMISSION RATE DUE TO TURBOCHARGING.

\begin{tabular}{|c|c|}
\hline $\begin{array}{c}C O_{x} \\
\text { Emission }\end{array}$ & $\begin{array}{c}\text { Density of air per } \\
\text { speed }\end{array}$ \\
\hline 8 & 2000 \\
\hline 10 & 1500 \\
\hline 12 & 1000 \\
\hline 14 & 500 \\
\hline 16 & 100 \\
\hline
\end{tabular}

Also, the increase in air density entering the engine ensures that there is complete combustion which creates more power and fewer emissions as shown in Figure 5.

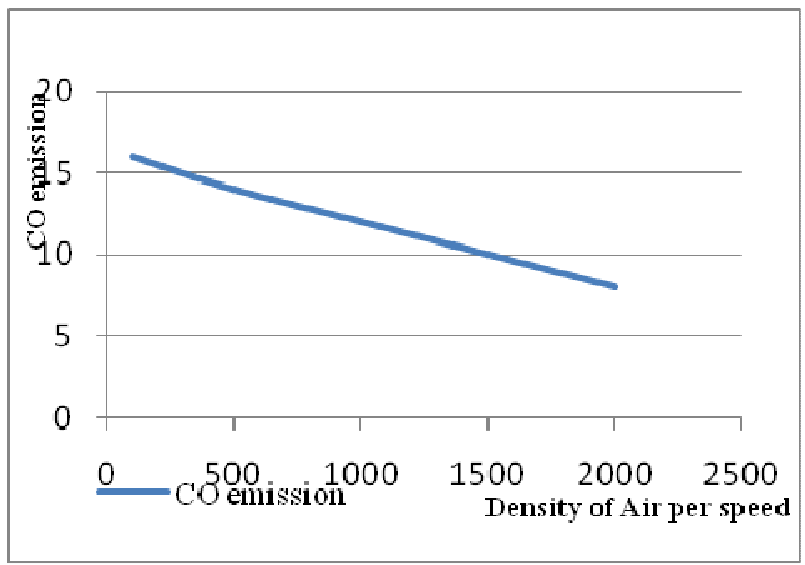

Fig. 5. Emission rate due to turbocharging

\section{CONCLUSION}

From the analysis carried out, the WHRS reduces the rate of air pollution from the vessel with respect to the number of steam drum and pressure. The rate at which fuel is burnt is reduced and this is based also on the number of steam drum and pressure. This analysis shows that the electrical needs on board can be met with the aid of a turbo generator with all the auxiliary set shut down while running at full load. This is made possible with the SPWHRS with about $2500 \mathrm{~kW}$ of energy saved to drive the turbo generator to produce electricity.

Seawater Scrubbing Technology is the water emulsion technology where emission control yields $1 \%$ reduction in $\mathrm{NO}_{\mathrm{x}}$ for $1 \%$ concentration of water. More so, the SCR process involves the use of reagent which will achieve up to $90 \%$ of $\mathrm{NO}_{\mathrm{x}}$ reduction. With the scrubbing system, it is possible to reduce the sulphur emission to a level as low as if low sulphur fuel oil was used. Despite the space factor, the maintenance cost and its complexity, the WHRS has its advantages as it increases fuel saving, cost saving and also reduces the exhaust gas emission.

The use of the above mentioned technologies if fully applied will reduce the emission rate. This implies that turbocharging would also help to reduce exhaust emission from diesel engines used in the maritime industry. Therefore, There is a need for Environmental Protection Agencies (EPAs) at all levels to assist in the enforcement of the above policies.

\section{RECOMMENDATIONS}

- Regulatory authorities all over the world should implement technical and operational measures to reduce global warming and pollution as soon as possible. Such measures include speed controls, weather routine, fuel switching and specialized hull coatings.

- Fleets should begin to implement longer-term measures to reduce global warming and pollution, such as fuel efficient design of new ships and engines created specifically for slow steaming.

- EPAs should find that the carbon dioxide, black carbon, nitrogen oxides and nitrous oxide emissions from ships significantly contribute to climate change and ocean acidification and therefore pose a threat to public health and welfare.

- EPAs should regulate global warming pollutants from ships operating within their various Exclusive Economic Zones. This can be done by setting emission standards and by requiring specific operational procedures, such as speed restrictions.

- The IMO should set international emission standards to reduce global warming pollutants from the shipping industry.

\section{ACKNOWLEDGEMENTS}

The authors of this work are extremely indebted to Mr Felix O. Akpobome and Mr. Kuvie A. Ejabefio for their help with data collection, manuscript drafting, typesetting and final formatting.

\section{REFERENCES}

[1] H. O. Kristensen, "Greenship of the Future, CO2-Neutralised Production", Rosendahls, Esbjerg, Denmark

[2] F. Van Haren, M. Kadlec, "Focus on diesel exhaust-air quality program: why is diesel exhaust a problem?", Washington State Department of Ecology, 2009

[3] E. A. Ogbonnaya, K. T. Johnson, C. U. Orji, "Reducing the impact of emissions on the environment from gas turbine exhaust", Proceedings of Nigerian Society of Engineers Annual General Meeting \& Conference, International Conference Center, Abuja 2010

[4] Healthy Building Network, Kaiser Permanente, "Toxic chemicals in building materials: an overview for health care organizations", Global Health and Safety Initiative-Health Care Without Harm, 2008

[5] United Nations Industrial Development Organization, "Ozone-friendly industrial development. impact and lessons learned. refrigeration and alternative technologies for domestic appliances", United Nations Industrial Development Organization, Vienna, 2003

[6] J. O. Hellmann, K. Aabo, Emission Control, Two-Stroke Low-Speed Diesel Engines, Inst. of Diesel and Gas Turbine Engineers, 1997

[7] Crystec Technology Trading GmbH, Dry Exhaust Gas Cleaner, SemaiAn Technology, https://www.crystec.com/ksicate.htm

[8] J. Cofala, M. Amann, C. Heyes, F. Wagner, Z. Klinont, M. Posch, W. Schopp, L. Tarasson, J. E. Johnson, C. Whall, A. Stavrakaki, "Analysis of Policy Measures to Reduce Ship Emissions in the Context of the Revision of the National Emission Ceilings Directives", International Institute for Applied Systems Analysis, Schlossplate 1, Laxemburg, Austria, 2007

[9] Siemens AG, "Waste Heat Recovery (WHR) System: Generating Energy from a Ship's Exhaust Gases", Siemens, Industry Sector, 
Industry Solutions Division, Hamburg, Germany, Reference number: IIS201009.684e fp, 2010

[10] Technical Data for Sulzer RLB Marine Diesel Engine, "The Sulzer RTFL ex Common-Rail System Described,” Wärtsilä Switzerland Ltd, PO Box 414, CH-8401, Winterthur, 2004 